\title{
Improvement of gastric inflammation and resolution of epithelial damage one year after eradication of Helicobacter pylori
}

Department of

Gastroenterology and Hepatology,

Nijmegen University

Hospital, PO Box

$9101,6500 \mathrm{HB}$

Nijmegen,

The Netherlands

E M Witteman

W P M Hopman

\section{Department of}

Pathology

M Mravunac

Department of Internal Medicine

M J C M Becx

R W de Koning

Statistical

Department,

Brocades Pharma

Yamanouchi Group,

Leiderdorp,

The Netherlands

J S C Verschoor

Department of Gastroenterology, Academic Medical

Centre, Amsterdam,

The Netherlands

G N J Tytgat

Correspondence to: Dr E M Witteman.

Accepted for publication 4 August 1994

E M Witteman, M Mravunac, M J C M Becx, W P M Hopman, J S C Verschoor, G N J Tytgat, $R$ W de Koning

\section{Abstract}

Aims-To investigate the effect of eradication of Helicobacter pylori infection on gastric epithelial damage and gastritis, scored according to the Sydney system. Methods-Gastritis scores and epithelial damage were assessed in gastric biopsy specimens before, and five weeks and one year after anti-H pylori therapy in 66 patients with $H$ pylori related gastritis. Results-The mean initial levels of activity, inflammation, atrophy, intestinal metaplasia, and $H$ pylori scores were higher in the antrum than in the corpus or fundus. Eradication of $\boldsymbol{H}$ pylori resulted in an improvement in the mean inflammatory score in antral biopsy specimens from 2.23 before treatment to 1.32 and $1 \cdot 06$, respectively, five weeks and one year after treatment. Corresponding values for fundic biopsy specimens were $1 \cdot 30$,
$0 \cdot 36$ and $0 \cdot 35$. Activity scores improved from 1.41 before treatment to 0.13 and zero, respectively, five weeks and one year after treatment in antral biopsy specimens and from 0.60 before treatment to zero in fundic biopsy specimens. Before treatment, epithelial damage was present in $51 \%$ of biopsy specimens taken from the antrum and $23 \%$ of those from the corpus. Five weeks after eradication of $H$ pylori none of the biopsy specimens revealed evidence of epithelial damage.

Conclusion-Eradication of $\boldsymbol{H}$ pylori is followed by a rapid, significant improvement in the gastritis score and resolution of epithelial damage in antral and fundic mucosa.

(f Clin Pathol 1995;48:250-256)

Keywords: Helicobacter pylori, gastric inflammation, epithelial damage, eradication.

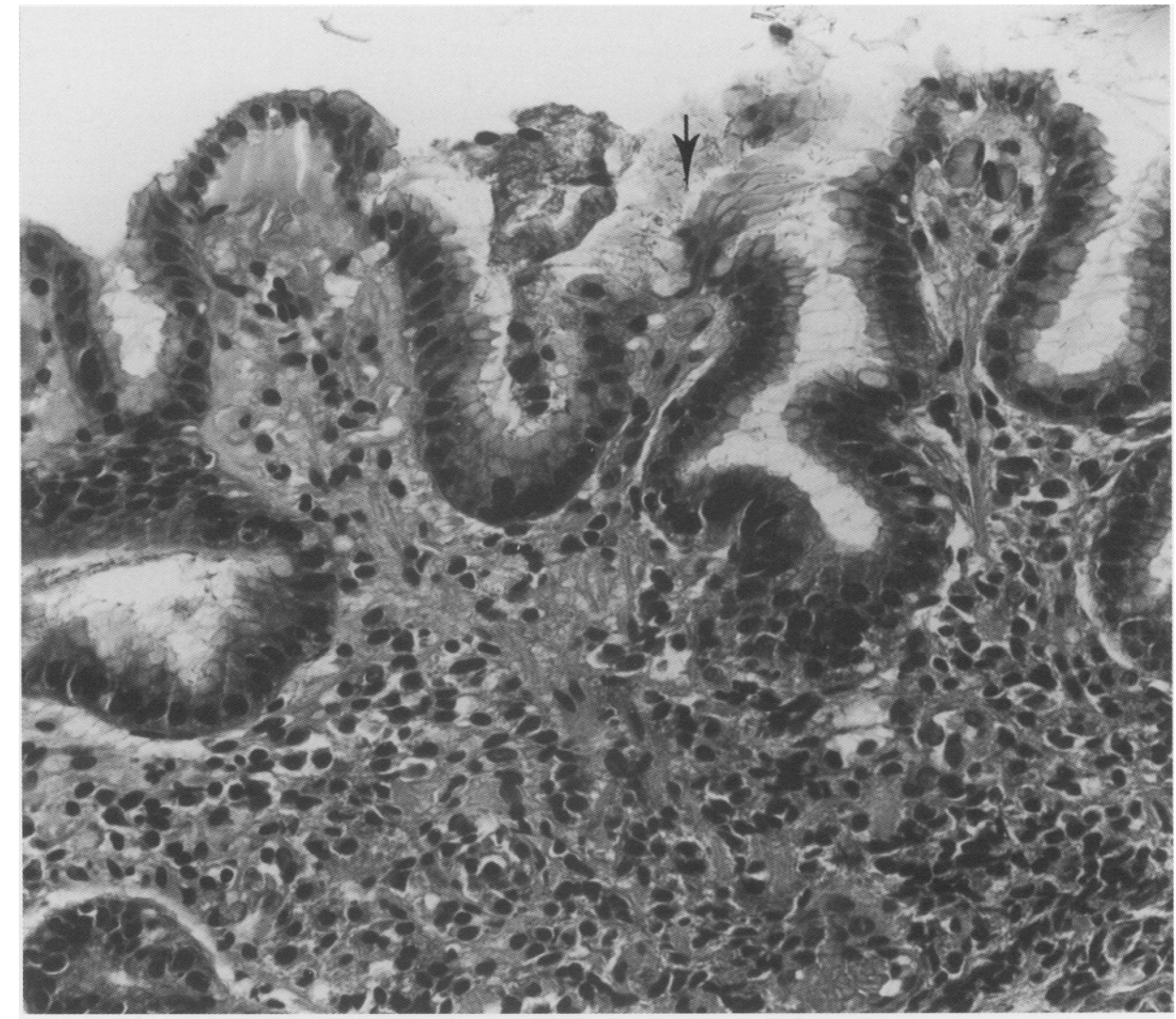

Figure $1 \mathrm{H}$ pylori associated chronic gastritis of the antrum showing severe active inflammation and epithelial damage. There are cellular tufts (arrow) alternating with depleted apical mucus (modified Giemsa). 


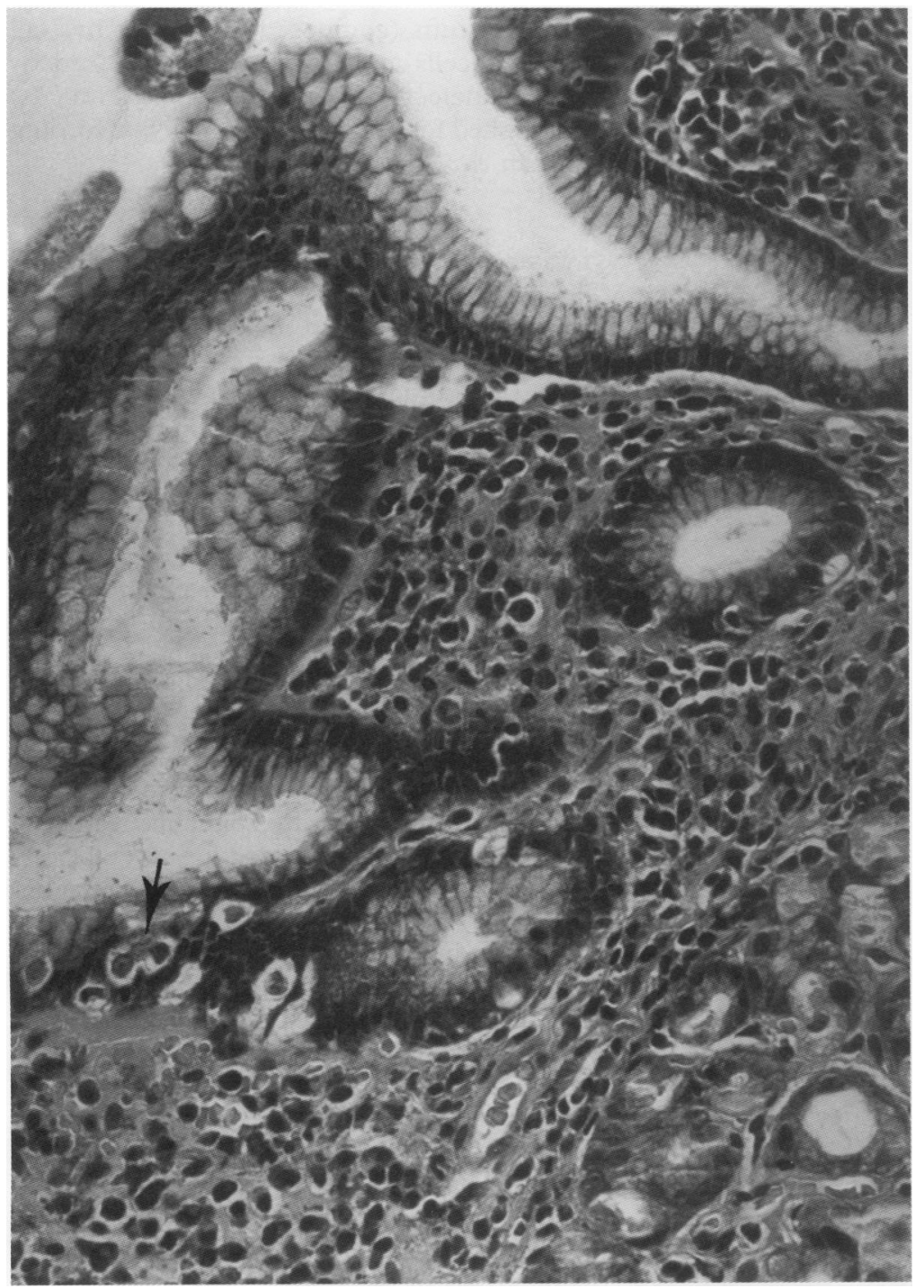

Figure $2 H$ pylori associated chronic gastritis of the fundus showing moderate active inflammation with intraepithelial infiltration of neutrophils (arrow) without epithelial damage (modified Giemsa). carried out using the Sydney system of scoring gastritis both before and after eradication of $H$ pylori in different parts of the stomach. ${ }^{1011}$ In particular, no study has systematically assessed the effect of eradication on epithelial damage. Surface epithelial degeneration has been a neglected aspect of $H$ pylori associated gastritis.

The aim of this study was to investigate the distribution of $H$ pylori, the degree of epithelial injury and the severity of gastritis, graded according to the Sydney system, and to assess improvements in the inflammatory changes and epithelial damage over one year of follow up after eradication of $H$ pylori in dyspeptic patients with gastritis.

\section{Methods}

Patients $(n=313)$ with upper abdominal symptoms of at least one month's duration and without endoscopic abnormalities other than gastritis were considered as candidates for our study. Of the 313 patients, 150 (48\%) had histological evidence of gastritis with concomitant $H$ pylori infection confirmed by culture or histology, or both. Of these 150 patients, 66 gave their written informed consent for participation in this trial. From this group, 35 patients were randomly selected to be treated with colloidal bismuth subcitrate (CBS) (120 mg four times daily for four weeks) and metronidazole (MTZ) (250 mg four times daily for 10 days); the remaining 31 patients were treated with CBS, $120 \mathrm{mg}$ four times daily, alone for four weeks, a standard regimen at the time of this study.

The patients underwent endoscopic examination before treatment, and five weeks and one year after cessation of treatment. The third endoscopy was performed earlier in cases in whom upper abdominal pain recurred.

On the first occasion, five antral biopsy specimens within a $5 \mathrm{~cm}$ radius of the pylorus, four biopsy specimens from the corpus (two proximal and two distal) and two fundic biopsy specimens were taken. Two antral biopsy specimens were cultured and three evaluated histologically. In 15 of the 66 patients only five antral, two fundic and no corpus specimens were taken. On the second and third endoscopies, five antral and two fundic biopsy specimens were taken. Eradication was defined as negative culture and histology at five weeks or more after completion of the therapy. $H$ pylori related micro-organisms were cultured as described previously. ${ }^{12}$

\section{HISTOLOGY}

The biopsy specimens were fixed in $10 \%$ buffered formalin, embedded in paraffin wax and stained with haematoxylin and eosin. $H$ pylori infection was assessed in both haematoxylin and eosin stained and modified Giemsa stained sections. All of the biopsy specimens were examined by the same pathologist (MM) who was unaware of the patients' treatment. The different variables for grading gastritis were rated on a four point scale ranging from zero to three; 0 , absent; 1 , mild; 2 , modand chronic inflammatory changes, atro and intestinal metaplasia in antral and corpus biopsy specimens. ${ }^{89}$ To date, however, few studies on the inflammatory response have been

Helicobacter pylori is widely accepted as an im associated inflammation plays an importan ease and is regarded as a risk factor for carcinoma. ${ }^{2-4}$ The prevalence of infectio age having rates approaching $60 \% . H$ pylor taneous recovery from infection is rare. The ecological niche of the micro-organism is the epithelial intercellular junctions. ${ }^{5}$ The gastric inflammation and epithelial injury. Epithelial damage such as disintegration of apical mucus, ypical of $H$ pylori colonisation. ${ }^{67}$ ney system, first introduced in 1990 . The histo- 


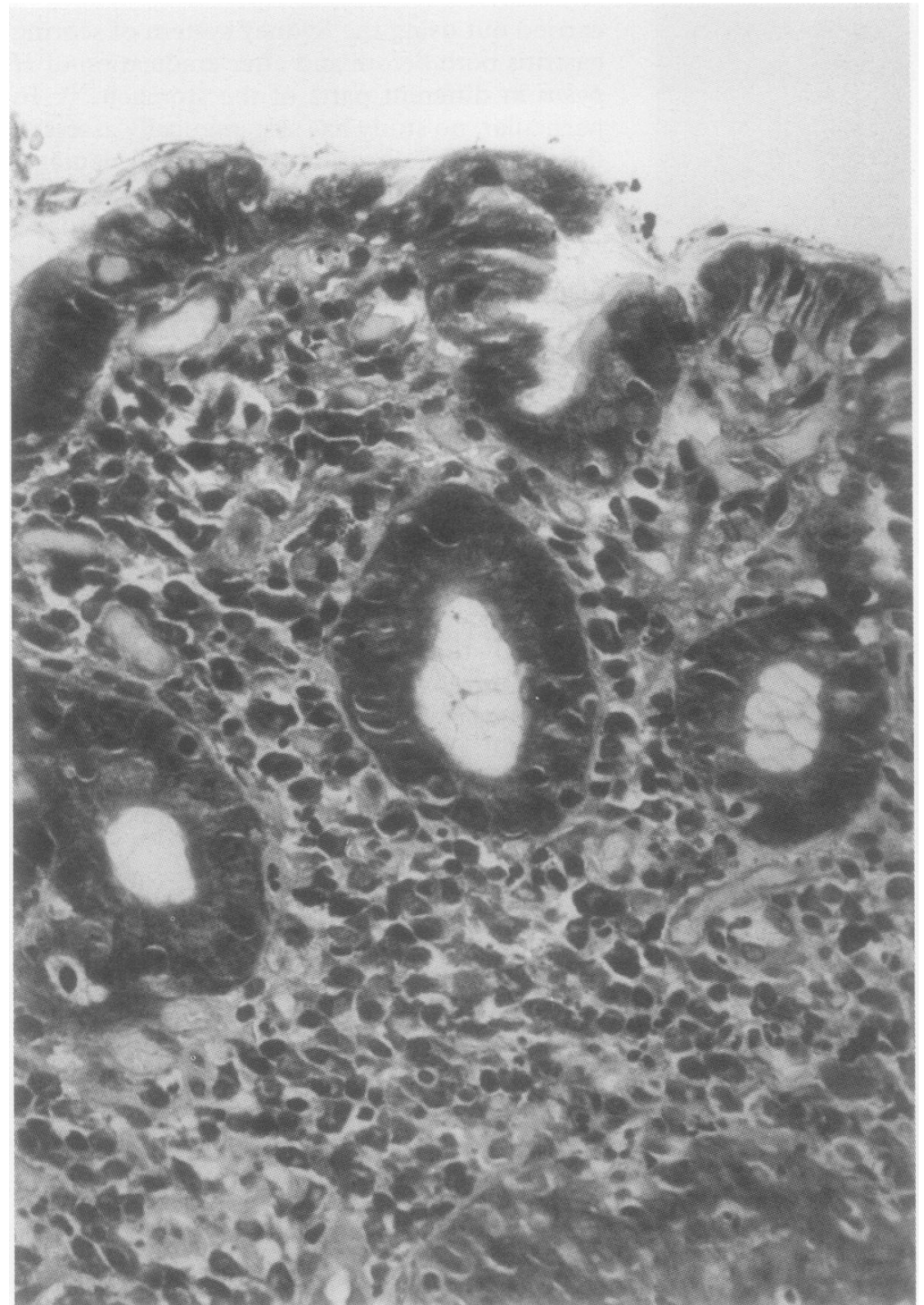

Figure $3 H$ pylori associated chronic gastritis of the antrum showing severe active inflammation and epithelial damage. There are multiple tufts alternating with depleted apical mucus (modified Giemsa). of cellular tufts (composed of three to five tall columnar cells and almost always flanked by epithelial defects and areas of depleted mucus) were looked for on light microscopy, according to Chan et al (figs 1-4). ${ }^{67}$

\section{STATISTICS}

The data were analysed using the non-parametric Wilcoxon signed rank test to determine whether the gastritis scores changed over time- that is, the score at time t compared with the pretreatment score (week 0). Comparisons between antral, corpus and fundic biopsy specimens were made using the Wilcoxon rank sum test. Spearman's rank correlation coefficients were computed for the association between the scores for $\mathrm{H}$ pylori and those for inflammation, activity, atrophy, metaplasia, and epithelial damage in the antral biopsy specimens. The $\chi^{2}$ test was used to investigate whether there was an association between epithelial damage and other aspects of the Sydney classification.

Because of the gradual withdrawal of a substantial proportion of the patients from the study because of worsening disease the estimates of mean histological parameters became increasingly less reliable towards the end of the study. To compensate for these difficulties, an intention to treat analysis was undertaken. Missing data for patients who withdrew prematurely from the study were generated using the last observation carried forward approach, where the last data collected for patients were fixed until the last time point (that is, one year after treatment). Thus, patients who withdrew because of deteriorating health were considered unchanged for the remaining part of the study.

\section{Results}

PRETREATMENT (MORPHOLOGICAL DATA)

Of the 66 patients, 62 had pangastritis, occurring most prominently in the antrum. The mean levels of all five different variables of the Sydney classification were significantly higher in the antral compared with the corpus and fundic biopsy specimens (Wilcoxon rank sum test, $\mathrm{p}<0.05$; fig 5 ). In one of the 66 patients more than two antral biopsy specimens were necessary to detect $H$ pylori-like microorganisms. In $43 \%$ of the patients there was activity in the antral biopsy specimens only and in $7 \%$ of the patients activity was present in corpus or fundic biopsy specimens only. In all patients antral biopsy specimens revealed chronic inflammation $(68 \%$ had grade 2 inflammation).

Lymphoid follicles were found in 38, 5 and $11 \%$, respectively, of the antral, corpus and fundic biopsy specimens from the $H$ pylori positive patients. There was a direct correlation between the presence of lymphoid follicles and presence of epithelial damage $\left(\chi^{2}\right.$ test, $\left.p<0.05\right)$. No significant correlation between the degree of $H$ pylori colonisation and the prevalence of lymphoid follicles was found.

Irregular surface epithelium, loss of apical mucus and cellular tufts were detected siginflammation. In addition to the criteria specified in the Sydney system the presence of an irregular gastric surface epithelium, depletion of epithelial cell apical mucus and the presence 


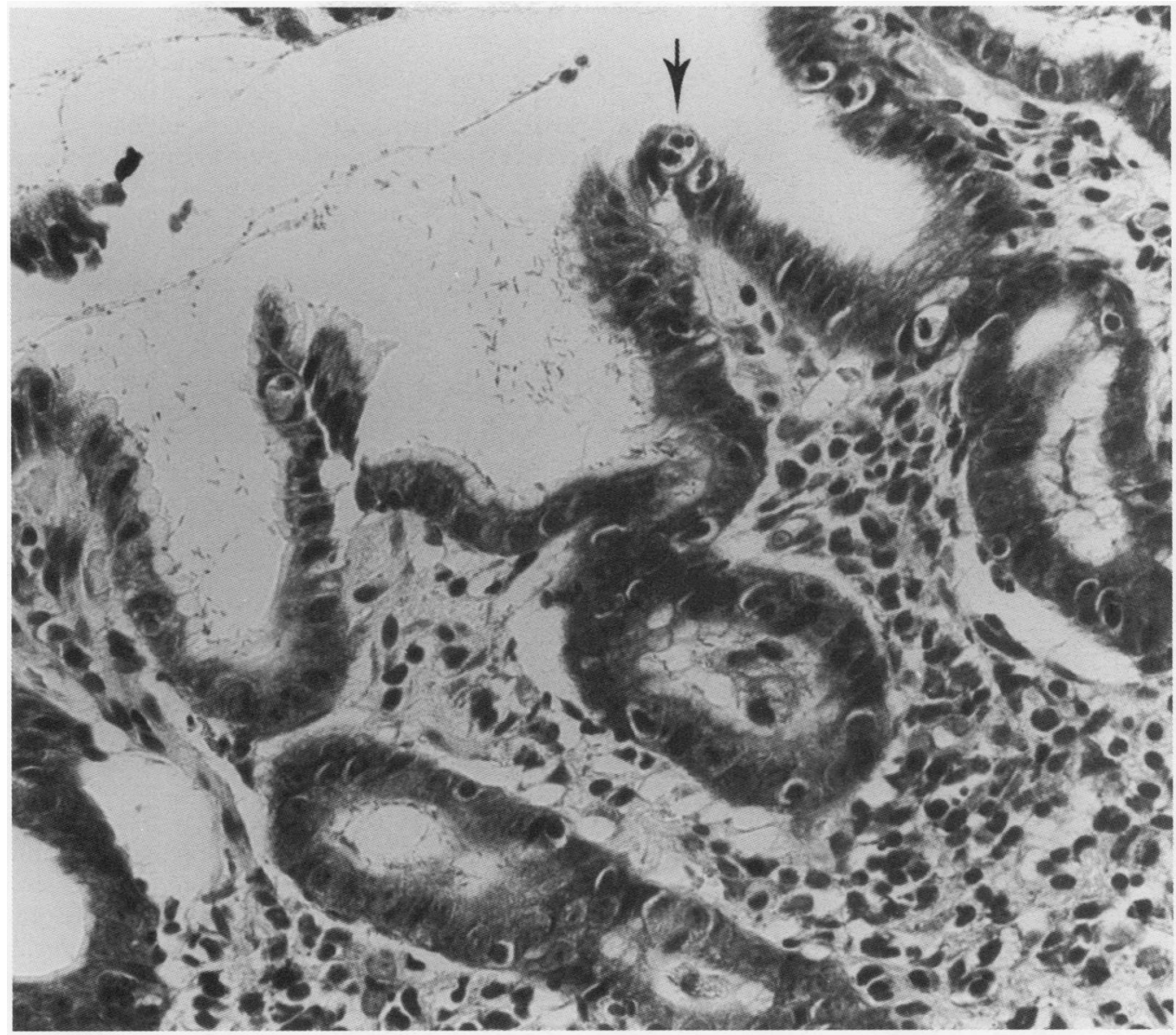

Figure 4 Chronic gastritis of the antrum showing multiple H pylori related micro-organisms, intraepithelial neutrophils and loss of mucus (arrow) (modified Giemsa).

Table 1 Mean ratings for the histological parameters, graded according to the Sydney system in antral and fundic biopsy specimens before therapy (week 0 ) and five weeks and one year after treatment in patients in whom $H$ pylor eradication was successful compared with those with persistent infection (intention to treat analysis)

\begin{tabular}{|c|c|c|c|c|}
\hline & $\begin{array}{l}\begin{array}{l}C B S \\
n=31\end{array} \\
\text { (not-eradicated) }\end{array}$ & $\begin{array}{l}C B S+M T Z \text { (not-eradicated) } \\
n=12\end{array}$ & $\begin{array}{l}C B S+M T Z \text { (eradicated) } \\
n=23\end{array}$ & $\begin{array}{l}\text { Eradicated } \\
+1-\end{array}$ \\
\hline \multicolumn{5}{|l|}{$\begin{array}{l}\text { Antrum } \\
\text { activity }\end{array}$} \\
\hline & $1 \cdot 4$ & $1 \cdot 3$ & 1.4 & \\
\hline 5 weeks & $1 \cdot 3$ & $1 \cdot 3$ & $0.3^{*}$ & $t$ \\
\hline 1 year & $1 \cdot 3$ & $1 \cdot 3$ & $0.3^{*}$ & $t$ \\
\hline \multicolumn{5}{|c|}{ inflammation } \\
\hline & $2 \cdot 2$ & $2 \cdot 2$ & $2 \cdot 3$ & \\
\hline 5 weeks & $2 \cdot 1$ & $2 \cdot 1$ & $1.5^{*}$ & $t$ \\
\hline 1 year & $2 \cdot 2$ & $2 \cdot 2$ & $1 \cdot 2^{*}$ & $\dot{t}$ \\
\hline \multicolumn{5}{|l|}{ metaplasia } \\
\hline & 0.5 & 0.4 & 0.3 & \\
\hline 5 weeks & 0.5 & $0 \cdot 6$ & $0 \cdot 1$ & \\
\hline 1 year & 0.6 & 0.7 & $0 \cdot 2$ & \\
\hline \multicolumn{5}{|l|}{ atrophy } \\
\hline & $0 \cdot 2$ & $0 \cdot 1$ & $0 \cdot 3$ & \\
\hline $\begin{array}{l}5 \text { weeks } \\
1 \text { year }\end{array}$ & 0.1 & 0.0 & $0 \cdot 2$ & \\
\hline 1 year & $0 \cdot 1$ & 0.0 & 0.2 & \\
\hline \multicolumn{5}{|l|}{$\begin{array}{l}\text { Fundus } \\
\text { activity }\end{array}$} \\
\hline & 0.9 & 0.3 & 0.5 & \\
\hline 5 weeks & 0.6 & 0.1 & $0 \cdot 1^{*}$ & \\
\hline 1 year & 0.7 & $0 \cdot 1$ & $0.0^{*}$ & \\
\hline \multicolumn{5}{|c|}{ inflammation } \\
\hline 0 & & 1.4 & 1.0 & \\
\hline 5 weeks & 1.4 & 1.3 & $0.5^{*}$ & $t$ \\
\hline 1 year & 1.4 & $1 \cdot 3$ & $0 \cdot 4^{*}$ & $t$ \\
\hline \multicolumn{5}{|l|}{ metaplasia } \\
\hline 0 & & & 0.0 & \\
\hline 5 weeks & 0.0 & $0 \cdot 1$ & 0.0 & \\
\hline 1 year & $0 \cdot 1$ & $0 \cdot 1$ & 0.0 & \\
\hline \multicolumn{5}{|l|}{ atrophy } \\
\hline 0 & $0 \cdot 0$ & $0 \cdot 0$ & $0 \cdot 0$ & \\
\hline $\begin{array}{l}5 \text { weeks } \\
1 \text { year }\end{array}$ & $\begin{array}{l}0.0 \\
0.0\end{array}$ & $\begin{array}{l}0.0 \\
0.0\end{array}$ & $\begin{array}{l}0.0 \\
0.0\end{array}$ & \\
\hline
\end{tabular}

${ }^{*} \mathrm{p}<0.05$ from baseline (pretreatment); $\uparrow \mathrm{p}<0.05$ between patients with and without $H$ pylori infection. 


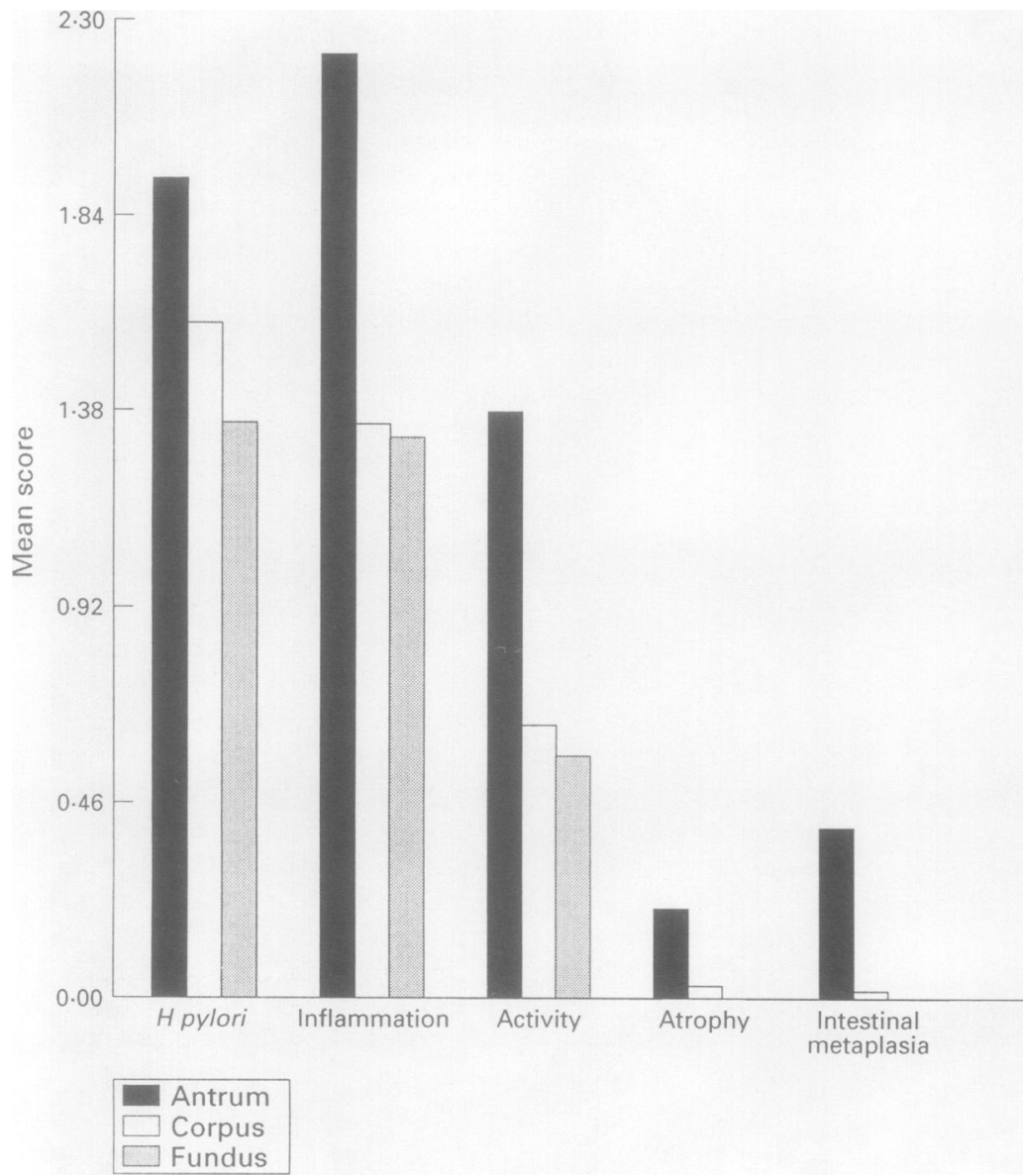

Figure 5 Mean scores of histological parameters according to the Sydney system on gastric biopsy specimens from patients with $H$ pylori related gastritis. The mean level of all five variables was significantly higher in antral compared with corpus and fundic biopsy specimens (Wilcoxon rank-sum test; $p<0.05$ ).

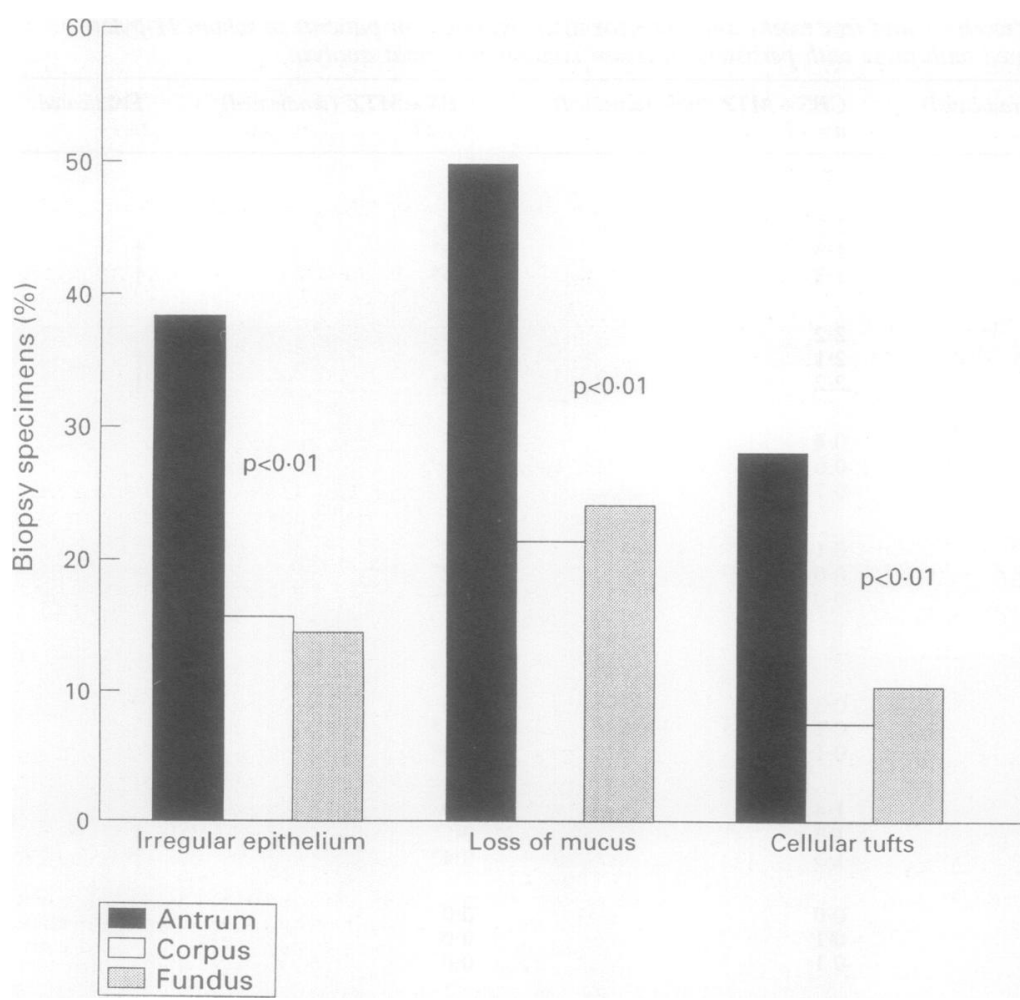

Figure 6 Percentage of biopsy specimens with epithelial damage in patients with $H$ pylori related gastritis in antrum, corpus and gastric fundus. Irregular surface epithelium, loss of apical mucus and cellular tufts occurred significantly more frequently in the antral than in the corpus or fundic mucosa $\left(\chi^{2}\right.$ test; $\left.p<0 \cdot 01\right)$. nificantly more frequently in the antral than in the corpus and fundic mucosa $\left(\chi^{2}\right.$ test, $p<0.01$; fig 6).

A significant, positive association (Spearman's rank correlation) was detected between the $H$ pylori score (Sydney system) and the score for inflammation $(\mathrm{p}<0.001)$ and for activity $(\mathrm{p}<0.001)$. No statistically significant association was observed between the grade of $H$ pylori infection and the scores for atrophy or intestinal metaplasia. Patients without epithelial damage had significantly lower scores for chronic inflammation $(p=0.05)$, activity $(p=0.02)$, atrophy $(p=0.04)$, and intestinal metaplasia $(p=0 \cdot 0005)$. No statistically significant association could be found with respect to the $H$ pylori score $(\mathrm{p}=0 \cdot 18)$.

\section{POST-TREATMENT MORPHOLOGICAL DATA}

At five weeks, $H$ pylori was eradicated in 23 of the 35 patients $(66 \%)$ treated with dual therapy, but in none of the 31 patients treated with CBS alone. Fifty of the 66 patients underwent a third endoscopy. Patients who withdraw from the study included those with persisting $\mathrm{H}$ pylori infection (10 of 43) and those in whom $H$ pylori infection had been eradicated (six of 23). Nine patients underwent the third endoscopy within nine months of finishing therapy because their symptoms recurred.

$H$ pylori-like micro-organisms persisted in all 33 patients positive at five weeks who underwent the third endoscopy. Reinfection had not occurred in any of the $17 \mathrm{H}$ pylori negative patients who underwent the third endoscopy. Statistically significant improvements in activity and chronic inflammation were observed in patients with successful $H$ pylori eradication following combination therapy (table). Such improvement was not observed in persistently $H$ pylori positive patients on either treatment regimen.

In patients whose $H$ pylori infection had been successfully eradicated epithelial injury (characterised by surface epithelial irregularity, loss of apical mucus or cellular tufts) in the fundic and antral mucosa was resolved, five weeks and one year after treatment, whereas epithelial injury was still present in patients with persistent $H$ pylori infection.

Five weeks and one year after treatment, lymphoid follicles were still present in seven of $23(30 \%)$ and one of $17(6 \%)$, respectively, antral biopsy specimens from $H$ pylori negative patients. No corresponding decrease in the prevalence of lymphoid follicles was seen in those with persistent $H$ pylori infection.

There were no significant changes in atrophy or intestinal metaplasia scores in antral and fundic biopsy specimens during follow up in patients with (non-eradicated) and without (eradicated) persistent $H$ pylori infection.

\section{Discussion}

$H$ pylori associated chronic inflammation may lead to the development of atrophy and intestinal metaplasia in the gastric mucosa. ${ }^{13}$ However, there remain many unanswered 
questions about the progression and distribution of chronic $H$ pylori related inflammation, activity, atrophy, and intestinal metaplasia and potential reversibility after $H$ pylori eradication.

The histological divisions of the Sydney classification permit the separate examination of the behaviour of acute and chronic inflammation in different parts of the stomach following $H$ pylori therapy.

Our results suggest that activity and epithelial damage resolve quite rapidly after eradication of $H$ pylori and therefore can be used as markers of successful therapy, confirming conclusions reached by other authors. ${ }^{1011}$ Resolution of chronic inflammation is a much slower process in all parts of the stomach and in most patients regression is still incomplete one year after eradication. In contrast to the study of $\mathrm{Di}$ Napoli et $a l,{ }^{10}$ in this study failure to eradicate $H$ pylori did not result in even a temporary improvement in antral gastritis scores after five weeks. The inflammatory reaction, the density of the layer of the bacteria and epithelial damage was greater in fundic than in antral biopsy specimens, confirming the findings of other authors. ${ }^{14-17}$ The reduction in inflammation in the corpus and fundus may be related to a lower density of $H$ pylori colonisation. We found that the intensity of gastritis was significantly related to the density of $H$ pylori, which is consistent with the findings reported by other investigators. ${ }^{16-19}$

In $48 \%$ of our patients with upper abdominal symptoms and no endoscopic abnormalities there was histological evidence of chronic gastritis. $H$ pylori negative antral gastritis represented $23 \%$ of all gastritis cases. All other patients with gastritis were positive for $H$ pylori infection. In the literature the incidence of $H$ pylori negative gastritis has been reported to vary from zero to $28 \% .^{141520} \mathrm{H}$ pylori was detected in biopsy specimens from the corpus and fundus in a few patients. It is possible that $H$ pylori infection cleared spontaneously in some patients because of an unfavourable gastric environment. In fact, in $60 \%$ of patients with $H$ pylori negative gastritis and moderate inflammation and activity there was evidence of intestinal metaplasia or atrophy, which are often associated with low acid output.

Chan and $\mathrm{Hui}^{6}$ described characteristic surface changes such as loss of cell mucus, epithelial erosions and cellular tufts around gastric ulcers of patients with $H$ pylori infection in contrast to the changes present in $H$ pylori negative patients with gastric ulcer disease. We found similar epithelial changes in many patients with $H$ pylori related gastritis in the absence of gastric ulceration. The sensitivity of the presence of cellular tufts and depletion of apical mucus on microscopy as markers for the presence of $H$ pylori (29 and 49\%, respectively) was much lower in the patients with gastritis in this study compared with the corresponding patient group in the study by Chan and Hui. ${ }^{6}$ We were surprised not to find a correlation between the density of $H$ pylori infection and evidence of epithelial damage. Leung et $a l^{21}$ reported an association between the degree of $H$ pylori colonisation and the severity of epithelial damage. A possible explanation for this discrepancy is that their scoring system graded both focal maximal severity as well as the overall extent of bacterial colonisation. The specificity of epithelial damage as a marker of eradication in our study was very high. In all biopsy specimens of patients in whom $H$ pylori had been eradicated epithelial damage resolved rapidly within five weeks of cessation of therapy. There was a significant association between the inflammatory reaction and the degree of epithelial damage.

Gastric lymphoid tissue is reported to develop in response to chronic infection by $H$ pylori and is associated with low grade $\mathbf{B}$ cell gastric lymphoma. ${ }^{22-24}$ Lymphoid follicles were found in $38 \%$ of antral biopsy specimens in this study and appeared to be pathognomonic of $H$ pylori infection. ${ }^{25}$ Lymphoid follicles disappeared slowly after eradication of $H$ pylori.

Atrophy and intestinal metaplasia did not resolve, at least during the short follow up period in this study. The development of atrophy and intestinal metaplasia is multifactorial and factors other than bacterial infection alone are presumably involved (for example, diet induced injury and bile reflux). ${ }^{2627}$ However, longitudinal studies report the increased prevalence of chronic gastritis and $H$ pylori infection as well as an increased prevalence of atrophy and intestinal metaplasia with increasing age. ${ }^{28}$ Furthermore, changes in the epidemiology of $H$ pylori have also resulted in changes in the epidemiology of atrophic gastritis and intestinal metaplasia and subsequently in the occurrence of gastric carcinoma or peptic ulcer disease. ${ }^{2930}$ Many questions about the natural history of chronic gastritis remain unanswered. The natural progression of chronic gastritis and the possible resolution of atrophy and intestinal metaplasia following the eradication of $H$ pylori merits further study.

We are grateful to $\mathrm{Mr} \mathrm{T}$ Hagendoorn for taking the photographs.

1 Dooley CP, Cohen H, Fitzgibbons PL, Bauer M, Appleman MD, Perez-Perez GI, et al. Prevalence of Helicobacter pylori infection and histologic gastritis in asymptomatic persons. N Engl f Med 1989;321:1562-6.

2 Graham DY, Lew GM, Klein PD, Evans DG, Evans DJ, Saeed ZA, et al. Effect of treatment of Helicobacter pylori infection on the long-term recurrence of gastric or duodenal ulcer. A randomized, controlled study. Ann Intern Med 1992;116:705-8.

3 Nomura A, Stemmerman GN, Chyou PH, Kato I, PerezPerez GI, Blaser MJ. Helicobacter pylori infection and gastric carcinoma among Japanese Americans in Hawaii. gastric carcinoma among Japanes

4 Eurogast Study Group. An international association between Helicobacter pylori infection and gastric cancer. Lancet 1993;341:1359-62.

5 Chen XG, Correa P, Offerhaus J, Rodriguez E, Fanney F, Hoffman E, et al. Ultrastructure of the gastric mucosa harboring Campylobacter-like organisms. Am $\mathcal{F}$ Clin Pathol 1986;86:575-82.

6 Chan WY, Hui PK, Chan JKC, Cheung PS, Ng CS, Sham $\mathrm{CH}$, et al. Epithelial damage by Helicobacter pylori in gastric ulcers. Histopathology 1991;19:47-53.

7 Hui PK, Chan WY, Cheung PS, Chan JKC, Ng CS. Pathological changes of gastric mucosa colonized by Helicobacter pylori. Hum Pathol 1992;23:548-56.

8 Misiewicz JJ, Tytgat GNJ, Goodwin CS, Price A, Sipponen $P$, Strickland R. The Sydney system: A new classification of gastritis. Working Party Reports. Sydney: World Congress of Gastroenterology, 1990:1-10.

9 Price AB. The Sydney System: Histological division. $\mathcal{f}$ Gastronterol Hepatol 1991;6:209-22.

10 Di Napoli A, Petrino R, Boero M, Bellis D, Chiandussi L. Quantitative assessment of histological changes in chronic gastritis after eradication of Helicobacter pylori. $\mathcal{F}$ Clin
Pathol 1992;45:796-8. 
11 Valle J, Seppälä K, Sipponen P, Kosunen T. Disappearance of gastritis after eradication of Helicobacter pylori. Scand $\mathcal{f}$ Gastroenterol 1991;26:1057-65.

12 Witteman EM, Hopman WPM, Becx MJCM, De Koning RW, Tytgat GNJ, Janssen AJHM, et al. Smoking habits and the acquisition of metronidazole resistance in patients with Helicobacter pylori-related gastritis. Aliment Pharmacol Ther 1993;7:683-7.

13 Craanen ME, Dekker W, Block P, Ferwerda J, Tytgat GNJ. Intestinal metaplasia and Helicobacter pylori: an endoscopic bioptic study of the gastric antrum. Gut 1992; 33:16-20.

14 Hazell SL, Hennessy WB, Borody TJ, Carrick J, Ralston $M$, Brady $\mathrm{L}$, et al. Campylobacter pyloridis gastritis. Dis$\mathrm{M}$, Brady $\mathrm{L}$, et al. Campylobacter pyloridis gastritis. Distribution of bacteria and associated infiammation in the
gastroduodenal environment. Am $\mathcal{F}$ Gastroenterol 1987;82:

$15 \mathrm{Li} \mathrm{YY,} \mathrm{Hu} \mathrm{PJ,} \mathrm{Du} \mathrm{GG,} \mathrm{Hazell} \mathrm{SL.} \mathrm{The} \mathrm{prevalence} \mathrm{of}$ Helicobacter pylori infection in the People's Republic of China. Am f Gastronterol 1991;86:446-9.

16 Loffeld RJLF, Potters HVPJ, Arends JW, Stobberingh E, Flendrig JA, van Spreeuwel WP. Campylobacter associated gastritis in patients with non-ulcer dyspepsia. f Clin Pathol 1988;41:85-8.

17 Satch K, Kimura K, Yoshida Y, Kasano T, Kihira K, Taniguchi Y. A topographical relationship between $\mathrm{H}$ pylori
and gastritis: quantitative assessment of $\mathrm{H}$ pylori in the and gastritis: quantitative assessment of $\mathrm{H}$ pylori

18 Stolte M, Eidt S, Ohnsmann A. Differences in Helicobacter pylori associated gastritis in the antrum and body of the stomach

19 Bayerdörffer E, Lehn N, Hatz R, Mannes GA, Dertel H, Sauerbruch $\mathrm{T}$, et al. Difference in expression of Helicobacter pylori gastritis in antrum and body. Gastroenterology 1992;102:1575-82.

$20 \mathrm{Hu}$ PJ, Li YY, Mitchell HM, Zhou MH, Chen MH, Du
GG, et al. Oxyntic and antral gastritis in the People's Republic of China: diagnosis and relationship of Helcobacter pylori. Am $¥$ Gastrenterol 1992;87:741-45.

21 Leung KM, Hui PK, Chan WY, Thomas TMM. Helicobacter pylori-related gastritis and gastric ulcer. $A m \mathcal{F}$ Clin Pathol 1992;98:569-74.

22 Stolte M, Eidt S. Lymphoid follicles in the antral mucosa: immune response to Campylobacter pylori? $\mathcal{f} \mathrm{Clin}$ Patho 1989;42:1269-71.

23 Parsonnet J, Hansen S, Rodriquez L, Gelb AB, Warnke RA, Jellum E, et al. Helicobacter pylori infection and gastric lymphoma. $N$ Engl f Med 1994;330:1267-71.

24 Hussell T, Isaacson PG, Crabtree JE, Spencer J. The response of cells from low-grade B-cell gastric lymphomas of mucosa-associated lymphoid tissue to Helicobacter pylori. mucosa-associated lymph

25 Wyatt JI, Rathbone BJ. Immune response of the gastric mucosa to Campylobacter pylori. Scand f Gastroenterol Suppl 1988;142:44-9.

26 Sobala GM, Pignatelli B, Schorah CJ, Bartsch H, Sanderson $\mathrm{M}$, Dixon MF, et al. Levels of nitrite, N-nitroso compounds, ascorbic acid and total bile acids in gastric juice of patients with and without precancerous conditions of the stomach. Carcinogenesis 1991;12:193-8.

27 Correa P, Cuello C, Fajardo LF, Haenszel W, Bolanos O, De Ramirez B. Diet and gastric cancer: nutrition survey in a high risk area. $\mathcal{F}$ Natl Cancer Inst 1983;70:673-8.

28 Sipponen P, Kekki M, Siurala M. The Sydney System: Epidemiology and natural history of chronic gastritis. $\mathfrak{f}$ Epidemiology and natural history of

29 Dixon MF, Sobala GM. Gastritis and duodenitis: the histopathological spectrum. Eur f Gastroenterol Hepatol 1992 4 (Suppl 2): :17-23

30 Sipponen P. Helicobacter pylori infection-a common worldwide environmental risk factor of gastric cancer? Endoscopy 1992;24:424-7. 